\title{
Non-precious metal fuel cell cathode catalyst based on non-pyrolyzed polyaniline-Fe-carbon black and polyaniline-Fe-graphene
}

\author{
Hannah Grace D. Geronimo ${ }^{1,2}$, Maria Krisandra Mendoza ${ }^{2}$, E Bernard John V. Tongol ${ }^{1,2,3}$ \\ ${ }^{1}$ Department of Chemistry, College of Science; ${ }^{2}$ The Graduate School; ${ }^{3}$ Research Center for the Natural \\ and Applied Sciences University of Santo Tomas, España Boulevard, Sampaloc, 1015 Manila, \\ Philippines
}

\begin{abstract}
In this research, polyaniline/Fe/graphene oxide (PANI/Fe/GO) and polyaniline/Fe/carbon black (PANI/Fe/CB) composites were chemically synthesized as cathode catalyst for oxygen reduction reaction. Surface and elemental characterization of the synthesized composites were done using scanning electron microscopy (SEM), Atomic force microscopy (AFM) and energy dispersive X-ray (EDX) analysis. Elemental analysis confirms the Fe metal content of the catalyst. SEM images of PANI presents globular microstructures while GO on the other hand displays sheet-like structure with a height of $0.889 \mathrm{~nm}$ based on AFM results. The electrocatalytic activity of the prepared Fe based catalyst composites was evaluated using cyclic voltammetry (CV), linear sweep voltammetry (LSV), and Chronoamperometry in $0.5 \mathrm{M}$ sulfuric acid purged with oxygen for $5 \mathrm{~min}$. Electrochemical characterization shows the electrocatalytic activities of PANI/Fe/CB with a current density of $3.98 \mathrm{~mA} / \mathrm{cm}^{2}$ and PANI/Fe/GO with a current density of $7.13 \mathrm{~mA} / \mathrm{cm}^{2}$. Chronoamperometric investigations illustrate that $\mathrm{Pt} / \mathrm{C}$ gave a more stable curve compared to PANI/Fe/GO. In comparison with the commercially available Pt/C catalyst with a current density of $0.99 \mathrm{~mA} / \mathrm{cm}^{2}$, it can be seen that the synthesized PANI/Fe/GO and PANI/Fe/CB composites gave higher current densities compared to the commercially available platinum/ carbon (Pt/C) indicating that these catalyst composites could be a promising catalyst for ORR.
\end{abstract}

Keywords: fuel cell, cathode catalyst, polyaniline, iron, graphene

\section{INTRODUCTION}

Fuel cells offer a promising source of renewable and clean energy, since they provide high energy densities and efficiencies compared to other conventional systems [1]. One group of fuel cell is the polymer electrolyte membrane fuel

*To whom correspondence should be addressed: bvtongol@ust.edu.ph cell (PEMFC). It has been recognized as a future power source for zero emission vehicles due to the fact that it efficiently generates high power density [2]. One type of PEMFC is the direct ethanol fuel cell (DEFC) which utilizes anhydrous or diluted ethanol as fuel. Ethanol (EtOH) offers a promising fuel for DEFCs because it can be produced in large quantities from biomass and is much less toxic than methanol [3]. The DEFC 
is therefore, an energy source with great potential.

The kinetics in DEFC is sluggish due to the complete ethanol oxidation requiring 12-electron transfer on the anode component. As the anode oxidizes the ethanol fuel, the cathode compartment undergoes oxygen reduction reaction (ORR) at the same time. The oxygen reduction reaction at the cathode compartment is also sluggish in nature and goes through 4electron transfer for complete reduction [4].

In response to this dilemma, researchers had developed a way to hasten the reactions happening at the anode and cathode component of fuel cells. Through the synthesis and design of metal-based catalysts, the slow reactions in DEFCs had been significantly resolved. Efforts on providing a solution for the slow kinetics of ORR in the cathode were made by using Ptbased catalyst. Pt-based catalyst on the cathode of PEMFCs is desirable for facilitating the slow oxygen reduction reaction (ORR) at the present technology [3, 5-8].

Although fuel cells pose many advantages over other energy sources, it also possesses challenges. The use of Pt metal as catalyst led to another problem regarding its commercialization [9]. The high cost of DEFC due to the high Pt loading is the most important factor that hinders the large-scale commercialization of this type of fuel cells. There have been numerous efforts to lower fuel cell costs by minimizing the platinum content in the catalyst layer. Another solution was the development of an inexpensive non-Pt cathodic catalyst [7].

Previous works have provided means to develop low-Pt and even Pt-free catalyst for DEFC. Transition metal-nitrogen-carbon nanomaterial complexes synthesized through pyrolysis were considered the most promising when it comes to ORR activity and stability while reducing the catalyst cost [10]. The class of non-precious catalyst for cathode which has merited the attention of DEFC technology was the pyrolyzed iron porphyrins [2]. The hypothesis involving the active sites of transition metalnitrogen complexes has been correlated to fuel cell performance; owing to the high nitrogen concentration in the porphyrin. Although the ORR performance has exhibited good initial activity, poor stability and conductivity have been the major challenge for these types of catalysts [2]. Thus, finding a stable nitrogen source for the nanomaterial complexes is an ongoing research.

Nitrogen containing polymers such as conductive polymers were used to improve the ORR activity of the catalyst. Conductive polymer containing transition metals and carbon supports such as carbon nanotubes (CNT) have been used as precursors for the preparation of electrocatalysts for ORR. CNT was employed as a support due to its large surface area and stability, but the limitations on ORR due to its chemically inert surfaces was seen as a barrier to catalytic activity [11].

Other options for carbon support have been explored to generate higher catalytic activity and stability. Graphene has been used as substrates to make hybrid nanomaterial applied to several applications like sensors, catalyst supports and anode materials for lithium ion batteries [12]. Graphene oxide compared to carbon alone was found to be a more effective carbon support due to its unique physical, chemical and electrochemical properties [13].

One of the most promising non-precious metal used in ORR is iron (Fe) supported on carbonaceous materials and doped with nitrogen [14]. The use of iron metal with polyaniline presents a catalyst not only for PEMFC but also for other types of fuel cells such as microbial fuel cells [7, 11, 15, 16]. Aside from fuel cell application, the Fe-N-C structure of the catalyst 
can also be used as catalyst for different reactions such as Fischer-Tropsch synthesis and oxygen evolution reactions apart from ORR in fuel cells $[17,18]$.

Owing to the many applications of the Fe-PANI$\mathrm{C}$ structured composites, it can be seen that the feasibility of using it for DEFC applications can be done. Thus, incorporation of nitrogen containing compounds with non-precious metal catalyst has gained progress in achieving both activity and stability.

This study focuses on the synthesis of nonpyrolyzed catalyst using iron metal precursor. The synthesis also incorporates polyaniline (PANI) as conductive polymer with graphene oxide and carbon black as the support.

\section{Methodology}

Materials and chemicals. Graphite powder was purchased from Graphtek and was used as received. Hexachloroplatinic acid hydrate $\left(\mathrm{H}_{2} \mathrm{PtCl}_{6}\right)(>99.9 \%)$ was purchased from Merck. Iron (III) hexahydrate, aniline, and ammonium peroxydisulfate $\left(\left(\mathrm{NH}_{4}\right)_{2} \mathrm{~S}_{2} \mathrm{O}_{8}\right)$ (APS) with $99 \%$ purity were purchased from Sigma Aldrich and were used as received.

\section{Synthesis of PANI/Fe/carbon black and PANI/}

Fe/GO catalyst. A high surface area carbon black and graphene oxide were used as carbonaceous supports. Graphene oxide was synthesized through modified Hummers' method. Aniline $(80 \mu \mathrm{L})$ was first dispersed with carbon black and graphene oxide in a hydrochloric acid solution $(0.5 \mathrm{M}, 100 \mathrm{~mL})$. The mixture was kept below $10^{\circ} \mathrm{C}$ while the oxidant, APS (0.20028 g) and the transition metal precursor $\mathrm{FeCl}_{3} \cdot 6 \mathrm{H}_{2} \mathrm{O}(3 \mathrm{mM})$ were added drop wise. The molar ratio of aniline to APS is $1: 1$ during the aniline polymerization. In order to reduce the metal to Fe, sodium borohydride was added. After continuous mixing for $24 \mathrm{~h}$ to allow the polyaniline that was formed to uniformly combine with the carbonaceous supports, the mixture containing the conductive polymer, transition metal and carbon supports was filtered, washed and dried in an oven at $60^{\circ} \mathrm{C}$ [19].

Instrumentation. All electrochemical measurements were performed using a 3electrode system at room temperature which uses a Pt rod and Ag/AgCl (saturated with 3M $\mathrm{KCl}$ ) electrode as the counter and reference electrode, respectively. The working electrodes used were composites of Pt/CB (Premetek, USA), PtFe/CB, Fe/CB, Fe/GO, Fe/PANI, PANI/ $\mathrm{Fe} / \mathrm{CB}$ and $\mathrm{PANI} / \mathrm{Fe} / \mathrm{GO}$ dropcasted on glassy carbon electrode (GCE). The GCE was polished first using emery paper (grade 1200-1500) and alumina. All electrochemical measurements were carried out using a potentiostat (EDAQ, Australia) manipulated by a software system (EChem, EDAQ) Surface morphology of the synthesized catalysts was investigated using Hitachi TM 3000 Table Top Microscope with an accelerating voltage of $15 \mathrm{kV}$. Height profile of the synthesized catalysts was observed using atomic force microscope (Park Systems XE-100). EDX was done using JEOL JSM 5310 SEM (Surface Physics Laboratory, DLSU, Manila) with an accelerating voltage of $15 \mathrm{kV}$. Catalyst powders were adhered on a carbon tape and placed in the SEM chamber for EDX analysis.

\section{ReSUlTS AND DISCUSSION}

The most promising catalyst investigated thus far is carbon supported metal-nitrogen materials such as cobalt, nickel, and iron. The nature and surface properties of carbon present in the catalysts have a significant impact on the resulting ORR activity and stability. It has been established that the requirement to achieve ORR active catalysts is the incorporation of nitrogen on carbon support with proper metal-nitrogen coordination. The problem now is achieving a higher catalytic activity by modifying supports [12]. 

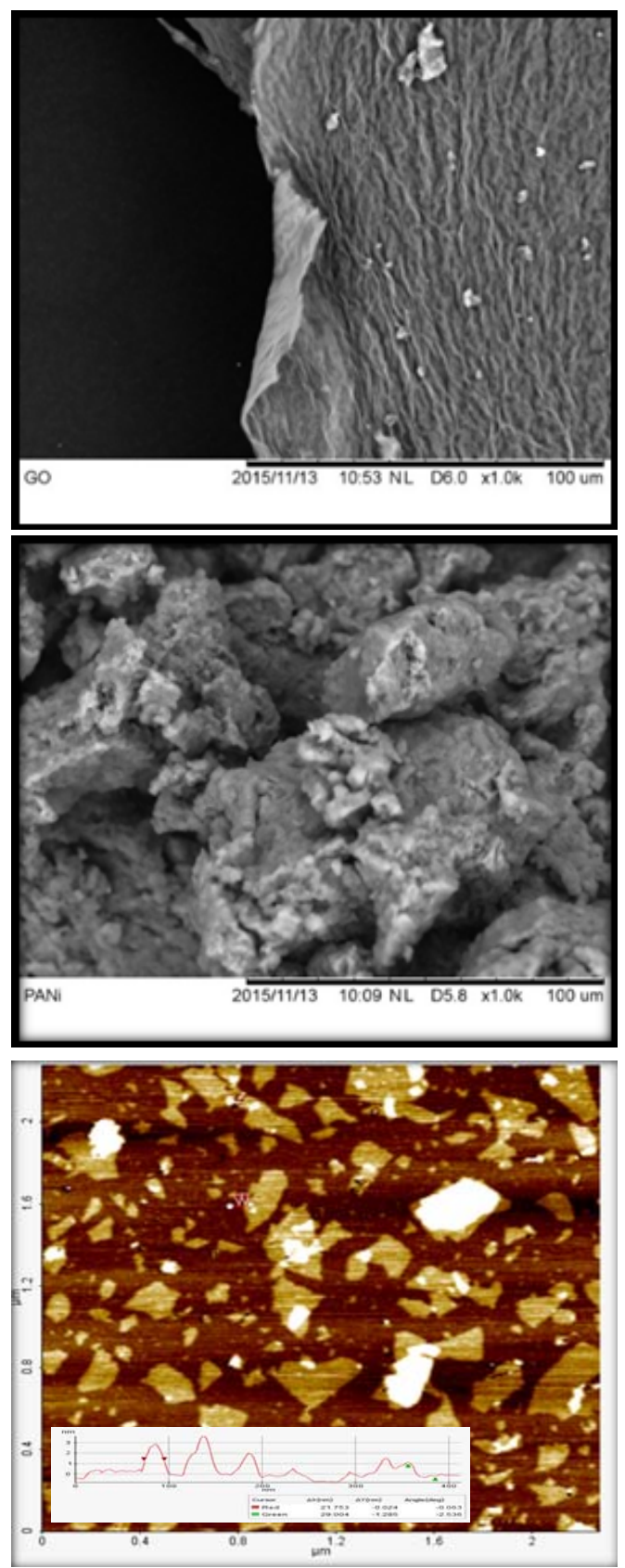

Fig. 1. SEM images of (A) graphene and (B) PANI at $1000 \times$, and (C) AFM image and line profile analysis of GO.
The synthesized graphene exhibited an SEM image (Fig. 1a) which showed the sheet-like and wrinkled morphology of the graphene, confirming the efficiency of the synthesis procedure. The AFM image of the synthesized graphene (Fig. 1c) indicated several graphene sheets with an average height or thickness of $0.728 \pm 0.109 \mathrm{~nm}$ which is a characteristic of graphene oxide [18]. The lateral dimension, on the other hand, had a range of $29 \mathrm{~nm}$ to $106 \mathrm{~nm}$ based on line profile analysis.

Conductive polymers such as polyaniline (PANI) characteristically display mixed metal and polymer like properties which are considered ideal for many applications due to their low cost, high electronic conductivity and distinct redox properties [19]. Based on calculations and experimental observations, it was claimed that the presence of electron donor heteroatoms influence the catalytic activity with nitrogen atoms providing the site for more activity enhancements [20]. The incorporation of transition metal complexes into the conductive polymer matrices was proposed to further improve the activity of carbon supported conductive polymer composites [2].

The SEM image of PANI (Fig. 1b) at 1000× magnification and $15 \mathrm{kV}$ presented a globular and cauliflower-like surface morphology [10]. The incorporation of the conductive polymer (PANI) with the graphene as support for the metallic catalyst has shown a different morphology as seen on Fig. 2a and 2b. The SEM image of Fe/PANI/CB (Fig. 2a) revealed a globular and rougher structure where PANI uniformly covered the CB support [21]. The SEM image of Fe/PANI/GO (Fig. 2b) exhibited a less rough surface with wrinkled structure at some areas [22]. The presence of the Fe metal as well as the $\mathrm{N}$ and $\mathrm{C}$ from the polyaniline with graphene support was confirmed using EDX elemental analysis (Fig. 2c). 

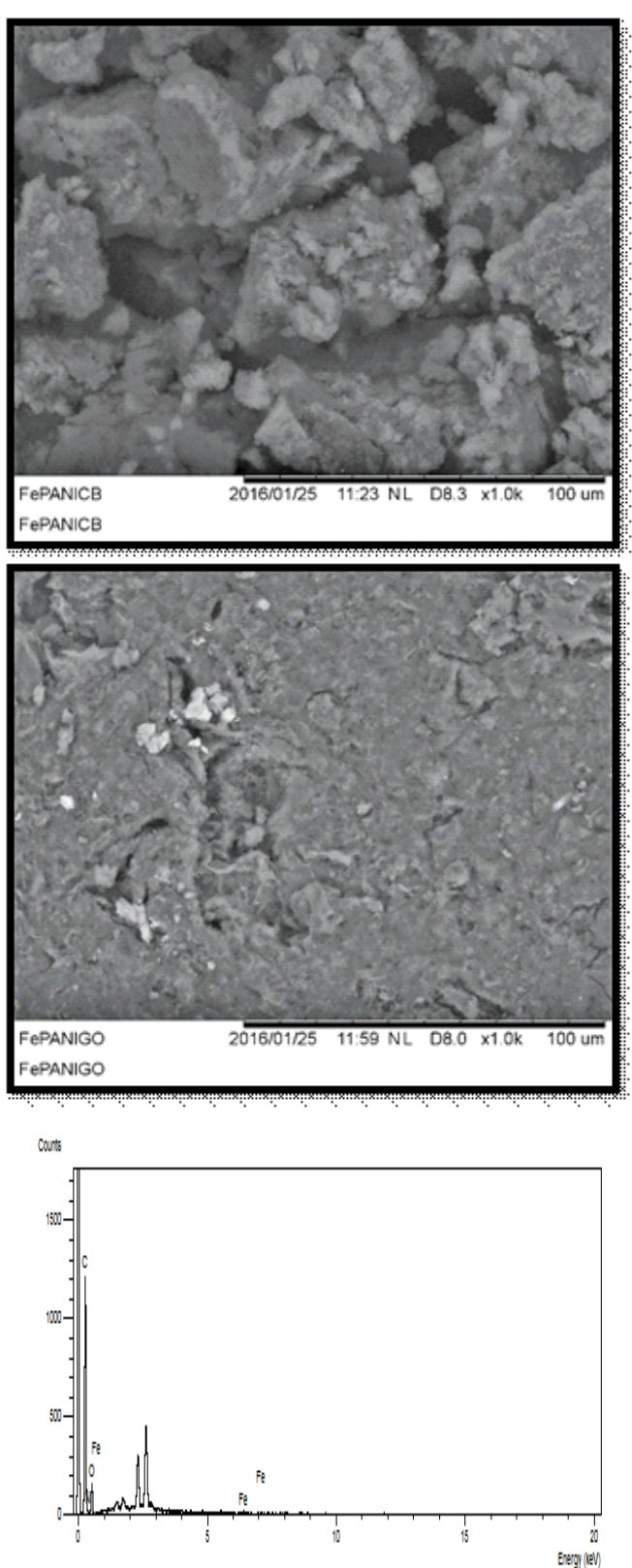

Fig. 2. SEM images of (A) Fe/PANI/CB and (B) Fe/ PANI/GO at $1000 \times$, and $(C)$ representative EDX spectra of $\mathrm{Fe} / \mathrm{PANI} / \mathrm{GO}$ catalyst

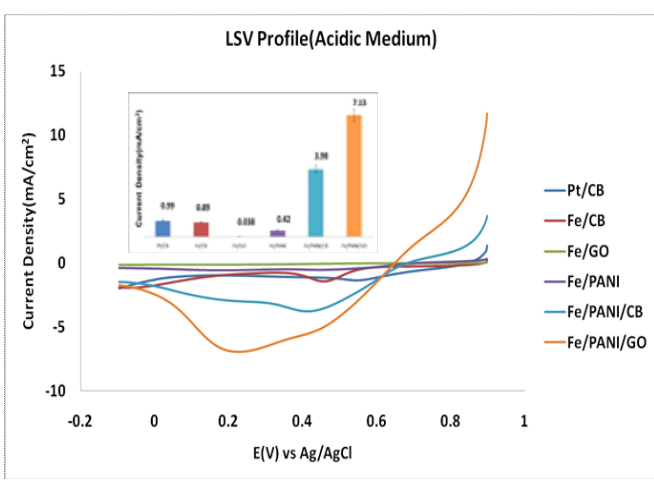

Fig. 3. LSV profile of different synthesized catalysts in $0.5 \mathrm{M} \mathrm{H}_{2} \mathrm{SO}_{4}$ electrolyte (saturated with oxygen for $5 \mathrm{~min}$ ) at $50 \mathrm{mV} / \mathrm{s}$

The linear-sweep voltammetry (LSV) profiles (Fig. 3) of the various synthesized catalysts measured in $0.5 \mathrm{M} \mathrm{H}_{2} \mathrm{SO}_{4}$ electrolyte and saturated with oxygen indicated that the $\mathrm{Fe}$ metal deposited on graphene, carbon black and PANI alone gave lower catalytic activities compared to commercially available Pt/CB. However, the combination of iron and the conductive polymer (PANI) and carbon supports (GO and $\mathrm{CB}$ ), achieved the highest ORR activity compared to the other synthesized catalysts and $\mathrm{Pt} / \mathrm{CB}$. A potential range of $-0.2 \mathrm{~V}$ to $1 \mathrm{~V}$ was used for each catalyst where ORR peaks can be seen between $0.2-0.8 \mathrm{~V}$, the potential range of Fe-PANI-C structured catalysts $[7,11,15,16]$.

The lowest catalytic activity obtained from $\mathrm{Fe} /$ GO catalyst can be due to the inefficient dispersion of graphene in the DFM solvent medium. While, the lower catalytic activity of Fe/PANI catalyst compared to Fe/CB catalyst can be attributed to the high surface area and good electrical and mechanical property of the carbon nanomaterial [23]. The coordination of nitrogen-ligand forming an active metal-nitrogen $(\mathrm{M}-\mathrm{N})$ structures in Fe/PANI which is not present in $\mathrm{Fe} / \mathrm{CB}$, was not enough to overcome the activity of Fe/CB [24]. Thus, the addition of nitrogen from PANI which coordinated the Fe 

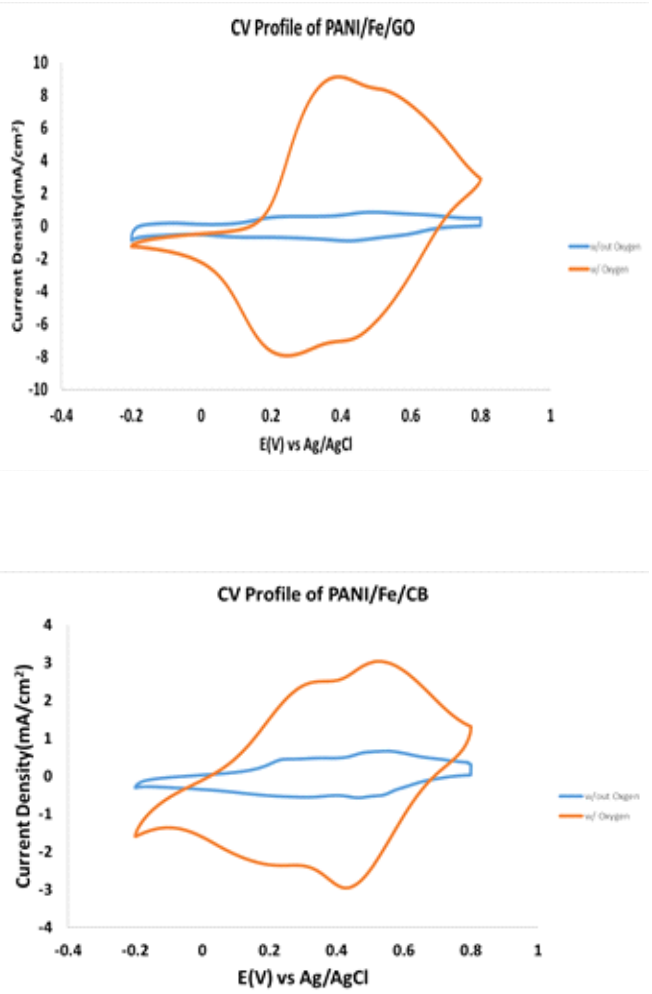

Fig. 4. $\mathrm{CV}$ profiles (5 ${ }^{\text {th }}$ cycle) of (A) Fe/PANI/GO and (B) $\mathrm{Fe} / \mathrm{PANI} / \mathrm{CB}$ catalyst composites at $50 \mathrm{mV} / \mathrm{s}$ in $0.5 \mathrm{M} \mathrm{H}_{2} \mathrm{SO}_{4}$ electrolyte with (orange curve) and without (blue curve) oxygen purging.

metal also enhanced the $\pi$ - $\pi$ stacking of the carbon support and PANI. The interaction of PANI and the carbon supports promoted electron transfer because PANI acting as a bridge formed M-N-C structures which increased catalytic activity [11].

PANI has three distinguishable oxidation states namely, the fully charged (leucomeraldine), halfoxidized (emeraldine) and fully oxidized (pernigraniline) which shows two sets of distinct redox activity as indicated by two pairs of anodic and cathodic current peaks [25]. CV measurement of Fe/PANI/GO (Figure 4) and Fe/ PANI/CB (Fig. 4b) was done in $0.5 \mathrm{M} \mathrm{H}_{2} \mathrm{SO}_{4}$ acid with and without $\mathrm{O}_{2}$ purging. It can be seen that the capacitive current increased after $\mathrm{O}_{2}$ purging

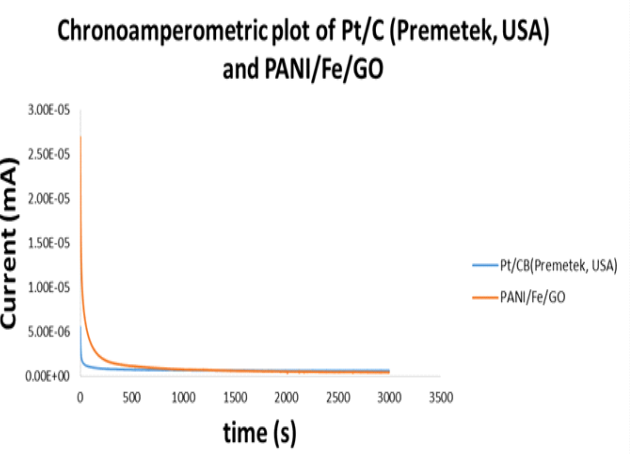

Fig. 5. Chronoamperometric plot of PANI/Fe/GO and $\mathrm{Pt} / \mathrm{CB}$ (Premetek, USA) in $0.5 \mathrm{M} \mathrm{H}_{2} \mathrm{SO}_{4}$ electrolyte at $0 \mathrm{~V}$ (saturated with oxygen for 20 min.)

but limitation on the ORR activity due to the metal precursors was not confirmed. The natural redox states of PANI can be seen as doping/dedoping peaks in Figure 3 [25], not seen on previous studies $[7,15,16]$ which used pyrolyzed PANI containing composites.

Figure 5 presents the chronoamperometric plots obtained for PANI/Fe/GO and Pt/CB. From these plots, it can be deduced that the two composites were continuously stable for 3000 sec. The relative stability of each catalyst was quantified by dividing the highest current from the plot by the starting current where stabilization was seen. The calculated relative stability of $\mathrm{Pt} / \mathrm{CB}$ is $2.42(1.67 \mathrm{~mA} / 0.689 \mathrm{~mA})$ while PANI/Fe/GO is 5.67 (3.69 mA/0.65 mA). These results indicate that $\mathrm{Fe} / \mathrm{PANI} / \mathrm{GO}$ is more stable than the commercially available Pt/CB.

The observed higher ORR activity and stability of the M-N-C catalyst can be attributed to the strong Fe-PANI interactions forming catalytically active sites, and the enhanced stability can be attributed to the aromatic nature of PANI which has a stronger interaction with the metal ion centers [26]. Comparison of the graphene and carbon black catalyst shows that the ordered graphitic-like structures of graphene 
could readily bind or form with the Fe metal precursor unlike carbon black which is dispersed and randomly distributed for the Fe metal precursor to bind with [27].

\section{CONCLUSION}

Catalyst composites consisting of PANI/Fe/CB and PANI/Fe/GO were chemically synthesized and characterized. Both catalyst composites gave rough morphologies with the PANI/Fe/CB catalyst giving a globular and aggregated surface indicative of PANI while for PANI/Fe/ GO catalyst, a wrinkled morphology can be seen indicative of graphene. Electrochemical characterization shows enhanced electrocatalytic activities towards ORR for PANI/Fe/CB (3.98 mA/ $\left.\mathrm{cm}^{2}\right)$ and PANI/Fe/GO $\left(7.13 \mathrm{~mA} / \mathrm{cm}^{2}\right)$ compared to Fe supported on pristine PANI, CB, or GO support and to commercial Pt/C.

\section{ACKNOWLedgment}

This work was funded by the Philippine Council for Industry, Energy, and Emerging Technology, Research and Development of the Department of Science and Technology (PCIEERD-DOST).

\section{REFERENCES}

[1] Serov A \& Kwak C. Recent achievements in direct ethylene glycol fuel cells (DEGFC). Applied Catalysis B: Environmental 2010, 97:1-12.

[2] Zelenay P \& Bashyam R. A class of non-precious metal composite catalysts for fuel cells. Nature 200, 443:63-66.

[3] Tayal J, Rawat B, \& Basu S. Bi-metallic and trimetallic Pt-Sn/C, Pt-Ir/C, Pt-Ir-Sn/C catalysts for electro-oxidation of ethanol in direct ethanol fuel cell. International Journal of Hydrogen Energy 2011, 36:14884-14897.

[4] Badwal SPS, Giddey S, Kulkarni A, Goe J, \& Basu S. Direct ethanol fuel cells for transport and stationary applications - A comprehensive review. Applied Energy 2015, 145:80-103.

[5] Antolini E. Catalysts for direct ethanol fuel cells. Journal of Power Sources 2007, 170:1-12.
[6] Mekhilef S, Saidur R, \& Safari A. Comparative study of different fuel cell technologies. Renewable and Sustainable Energy Reviews 2012, 16:981- 989.

[7] Mo Z, Peng H, Liang $\mathrm{H}$, \& Liao S. Vesicular nitrogen doped carbon material derived from $\mathrm{Fe}_{2} \mathrm{O}_{3}$ templated polyaniline as improved non-platinum fuel cell cathode catalyst, Electrochimica Acta 2013, 99:30-37.

[8] Song T, Wang D, Wang H, Li X, Liang Y, \& Xie J. Cobalt oxide/nanocarbon hybrid materials as alternative cathode catalyst for oxygen reduction in microbial fuel cell. International Journal of Hydrogen Energy 2015, 40(10):3868-3874.

[9] O'hayre R, Cha S, Colella W, \& Pring F. Fuel Cell Fundamentals, $2^{\text {nd }}$ Ed. John Wiley \& Sons Inc. (USA), 2009.

[10] Zamani P, Higgins D, Hassan F, Jiang G, Wu J, \& Abureden S. Electrospun Iron-PolyanilinePolyacrylonitrile derived nanofibers as non-precious Oxygen Reduction Reaction catalyst for PEM Fuel Cells. Electrochimica Acta 2013, 139:111-116.

[11] Hu T, Yin Z, Guo J, \& Wang C. Synthesis of Fe nanoparticles on polyaniline covered carbon nanotubes for oxygen reduction reaction. Journal of Power Sources 2014, 272:661-671.

[12] Vadahanambi S, Lee S, Kim W, \& Oh I. Arsenic Removal from Contaminated Water Using ThreeDimensional Graphene-Carbon Nanotube-Iron Oxide Nanostructures. Environmetal Science and Technology 2013, 47:10510-1051.

[13] Lorestani F, Shahnavaz Z, Mo P, Alias Y, \& Manan $N$. One-step hydrothermal green synthesis of silver nanoparticle-carbon nanotube reduced graphene oxide composite and its application as hydrogen peroxide sensor. Sensors and Actuators B 2015, 208:389-398.

[14] Gu L, Jiang L, Li X, Jin J, Wang J, \& Sun G. A Fe N C catalyst with highly dispersed iron in carbon for oxygen reduction reaction and its application in direct methanol fuel cells. Chinese Journal of Catalysis 2016, 37:539-548.

[15] Lai B, Wang P, Li H, Du Z, Wang L, \& Bi S. Calcined polyaniline-iron composite as a high efficient cathodic catalyst in microbial fuel cells. Bioresource Technology 2013, 131:321-324.

[16] Ferrandon M, Wanga X, Kropf J, Myersa D, Wub G, Johnston C, \& Zelenay P. Stability of iron species in heat-treated polyaniline-iron-carbon polymer electrolyte fuel cell cathode catalysts. Electrochimica Acta 2013, 110: 282-291. 
[17] Chen Z, Higgins D, Yu A, Zhang L, \& Zhang J. A review on non-precious metal electrocatalysts for PEM fuel cells. Energy \& Environmental Science 2011, 4(9):3167-3192.

[18] Si Y \& Samulsk E. Synthesis of Water-Soluble Graphene. Nanoletters 2008, 8:1679-1682.

[19] Daraei P, Madaeni SS, Ghaemi N, Salehi E, Khadivi MA, Moradian R, \& Astinchap B. Novel polyethersulfone nanocomposite membrane prepared by $\mathrm{PANI} / \mathrm{Fe}_{3} \mathrm{O}_{4}$ nanoparticles with enhanced performance for $\mathrm{Cu}$ (II) removal from water. Journal of Membrane Science 2012, 415416:250-259.

[20] Khomenko V, Frackowiak E, \& Beguin F. Determination of the specific capacitance of conducting polymer/nanotubes composite electrodes using different cell configurations. Electrochimica Acta 2005, 50(12):2499-2506.

[21] De A, Adhikary R, \& Datta J. Polyaniline/Carbon black nanocomposites: Proactive role of carbon nanotube-polyaniline conjugate support for $\mathrm{Pt}$ nano-particles toward electro-catalysis of ethanol in fuel cell. International Journal of Hydrogen Energy 2017, 42:5316-25325.

[22] Ma L, Su L, Zhang J, Zhao D, Qin C, Jin Z, \& Zhao K. A controllable morphology GO/PANI/metal hydroxide composite for supercapacitor. Journal of Electroanalytical Chemistry 2016, 777:7584.
[23] Wu G, Santandreu A, Kellogg W, Gupta S, Ogoke $\mathrm{O}$, Zhang $\mathrm{H}$, Wang $\mathrm{HL}$, \& Dai L. Carbon nanocomposite catalysts for oxygen reduction and evolution reactions: From nitrogen doping to transition-metal addition. Nano Energy 2016, 29:83-110.

[24] Shi KM, Cheng X, Jia Z, Guo J, Wang C, \& Wang J. Oxygen reduction reaction of Fe-Polyaniline/ Carbon Nanotube and Pt/C catalysts in alkali media. International Journal of Hydrogen Energy 2016, 1-10.

[25] Wallace G, Spinks G, Kane-Maguire L, \& Teasdale P. Conductive Electroactive Polymers (Intelligent Materials Systems), $2^{\text {nd }}$ Ed. CRC Press LLC (New York, Washington D.C.), 2003.

[26] Wei Y, Fang F, Yang W, Guo H, Niu X, \& Sun L. Preparation of a Nitrite Electrochemical Sensor Based on Polyaniline/GrapheneFerrocenecarboxylic acid Composite Film Modified Glassy Carbon Electrode and its Analytical Application. Journal of the Brazilian Chemical Society 2015, 26(10):2003-2013.

[27] Zhao Y, Chen H, Li J, \& Chen C. Hierarchical MWCNTs/ $\mathrm{Fe}_{3} \mathrm{O}_{4}$ /PANI magnetic composite as adsorbent for methyl orange removal. Journal of Colloid and Interface Science 2015, 450:189195. 